\title{
Source attribution and process analysis for atmospheric mercury in eastern China simulated by CMAQ-Hg
}

\author{
J. Zhu ${ }^{1,2}$, T. Wang ${ }^{1}$, J. Bieser ${ }^{3,4}$, and V. Matthias ${ }^{3}$ \\ ${ }^{1}$ School of Atmospheric Sciences, Nanjing University, Nanjing 210093, China \\ ${ }^{2}$ Department of Energy and Environment, Zhejiang Prov. Development Planning \& Research Institute, Hangzhou 310012, \\ China \\ ${ }^{3}$ Institute of Coastal Research, Helmholtz-Zentrum Geesthacht, Max-Planck-Str. 1, 21502, Geesthacht, Germany \\ ${ }^{4}$ National aeronautics and space research center (DRL), Oberpfaffenhofen, 82234, Weßling, Germany
}

Correspondence to: T. Wang (tjwang@ @ju.edu.cn)

Received: 19 February 2015 - Published in Atmos. Chem. Phys. Discuss.: 9 April 2015

Revised: 15 July 2015 - Accepted: 27 July 2015 - Published: 10 August 2015

\begin{abstract}
The contribution from different emission sources and atmospheric processes to gaseous elemental mercury (GEM), gaseous oxidized mercury (GOM), particulate bound mercury (PBM) and mercury deposition in eastern China were quantified using the Community Multi-scale Air Quality (CMAQ-Hg) modeling system run with a nested domain. Natural sources (NAT) and six categories of anthropogenic mercury sources (ANTH) including cement production (CEM), domestic life (DOM), industrial boilers (IND), metal production (MET), coal-fired power plants (PP) and traffic (TRA) were considered for source apportionment. NAT were responsible for $36.6 \%$ of annual averaged GEM concentration, which was regarded as the most important source for GEM in spite of obvious seasonal variation. Among ANTH, the influence of MET and PP on GEM were most evident especially in winter. ANTH dominated the variations of GOM and PBM concentrations with contributions of 86.7 and $79.1 \%$, respectively. Among ANTH, IND were the largest contributor for GOM $(57.5 \%)$ and PBM $(34.4 \%)$ so that most mercury deposition came from IND. The effect of mercury emitted from out of China was indicated by a $>30 \%$ contribution to GEM concentration and wet deposition. The contributions from nine processes - consisting of emissions (EMIS), gas-phase chemical production/loss (CHEM), horizontal advection (HADV), vertical advection (ZADV), horizontal advection (HDIF), vertical diffusion (VDIF), dry deposition (DDEP), cloud processes (CLDS) and aerosol processes (AERO) - were calculated for process analysis with their comparison in urban
\end{abstract}

and non-urban regions of the Yangtze River delta (YRD). EMIS and VDIF affected surface GEM and PBM concentrations most and tended to compensate each other all the time in both urban and non-urban areas. However, DDEP was the most important removal process for GOM with 7.3 and $2.9 \mathrm{ng} \mathrm{m}^{-3}$ reduced in the surface of urban and non-urban areas, respectively, in 1 day. The diurnal profile variation of processes revealed the transportation of GOM from urban area to non-urban areas and the importance of CHEM/AERO in higher altitudes which partly caused diffusion of GOM downwards to non-urban areas. Most of the anthropogenic mercury was transported and diffused away from urban areas by HADV and VDIF and increased mercury concentrations in non-urban areas by HADV. Natural emissions only influenced CHEM and AERO more significantly than anthropogenic. Local emissions in the YRD contributed $8.5 \%$ more to GEM and $\sim 30 \%$ more to GOM and PBM in urban areas compared to non-urban areas.

\section{Introduction}

Mercury $(\mathrm{Hg})$ pollution in the atmosphere attracts increasing concern globally in view of its neurotoxicity and bioaccumulation along the food chain posing risks to human health (Schroeder and Munthe, 1998; Rolfhus et al., 2003). Atmospheric mercury is divided into three species according to various physical and chemical properties: gaseous elemental mercury (GEM), gaseous oxidized mercury (GOM) and 
particulate bound mercury (PBM). GEM is the predominant form (>95\%) in atmosphere; it is very stable and well mixed hemispherically with a long lifetime of $0.5-2$ years (Selin et al., 2007). In contrast, GOM and PBM will deposit more rapidly downwind of their emission sources via wet or dry deposition since GOM and PBM have significantly higher reactivity, deposition velocities, and water solubility (Lin and Pehkonen, 1999; Lindberg et al., 2002; Keeler et al., 2005). Accordingly, mercury is a multi-scale pollutant able to be transported at local-, regional- and larger-scale distances from its sources, and mercury emission speciation has a great impact on the processes and spatial distribution of mercury in the atmosphere (Bieser et al., 2014; Quan et al., 2009; Pai et al., 1999).

Mercury is released into the atmosphere from both natural processes and anthropogenic activities. Natural processes such as evasion from soils, water bodies and vegetation just emit GEM with evident seasonal variation (Shetty et al., 2008). The natural sources will also include re-emission of anthropogenic mercury deposited into the environment previously (Gbor et al., 2006). Mercury emissions from anthropogenic sources are mainly from coal combustion, nonferrous smelters, waste incineration and mining (Streets et al., 2009). Anthropogenic mercury emissions in Asia are the highest in the world, accounting for about half of the global total (Pacyna et al., 2010). Moreover, China is considered as one of the largest and growing source regions due to its rapid economic and industrial growth along with a coal-dominated energy structure (Wu et al., 2006; Wang et al., 2014). Particularly high emissions of mercury in China result in a more elevated mercury concentration and larger mercury deposition than background levels in the world even in remote areas such as the Mt. Gongga area (Fu et al., 2008) and Mt. Changbai (Wan et al., 2009). Much more serious atmospheric mercury pollution was detected in Chinese urban sites where total gaseous mercury (TGM) concentrations were a factor of 3-5 higher than those observed in rural areas (Zhu et al., 2012; Chen et al., 2013; Feng et al., 2004, Zhang et al., 2013). Therefore, a better understanding of the source-receptor relationships for mercury and availability of valuable information on mercury transport, deposition and chemistry within China are urgently needed. Detailed quantitative assessments of the contributions of mercury sources help to determine effective mercury emission control strategies.

Previous publications provided contribution estimates from selected emission sources mostly in the United States (Seigneur et al., 2004; Selin and Jacob, 2008; Lin et al., 2012) and the Great Lakes region (Cohen et al., 2004; Holloway et al., 2012) using global and regional chemical transport models. Many studies for Asia focus on the mercury mass outflow caused by the total emission in Asia and its contribution to long-range transport (Pan et al., 2010; Lin et al., 2010). Limited source apportionment of mercury pollution in China has been studied by Wang et al. (2014), distinguishing four emission sectors using a global model (GEOS-Chem) in coarse spatial resolution. In addition, few studies focus on diagnostic and process analyses for atmospheric mercury pollution formation and identification of the dominant atmospheric processes for mercury. The mercury version of US EPA's Community Multi-scale Air Quality (CMAQ-Hg) modeling system (Bullock and Brehme, 2002) was widely used to simulate regional atmospheric mercury pollution. Process analysis (PA) embedded in CMAQ can be applied to investigate the relative contribution of the individual processes on simulated concentration. The performance of the CMAQ-Hg model in simulating mercury has been evaluated against mercury concentration and deposition measured at the surface mostly in the USA (Holloway et al., 2012; Bullock et al., 2008, 2009; Gbor et al., 2006, 2007).

In this paper, the temporal and spatial distributions of atmospheric mercury and its deposition in 2011 were simulated on a nested domain over eastern China with grid a resolution of $27 \mathrm{~km} \times 27 \mathrm{~km}$ and parent grid resolution of $81 \mathrm{~km} \times 81 \mathrm{~km}$ using CMAQ-Hg. The model results were compared to available monitoring data. Seasonal contributions of all types of mercury emission sources - including natural emissions, cement plants, domestic coal burning, industrial boilers, metal productions, power plants and traffic emissions - to atmospheric mercury concentration and deposition were quantified. The process analysis for atmospheric mercury concentration was used for select urban and nonurban areas. The influence of physical and chemical processes on mercury concentration was examined. This study provides a detailed model study on source apportionment and process analysis of atmospheric mercury in eastern China.

\section{Methods}

\subsection{Model descriptions}

The model used in this study was based on CMAQ v4.6, which has been modified by Bullock and Brehme (2002) and Gbor et al. (2006) to include chemistry, transport and deposition of GEM, GOM and PBM. The model was configured to use the Carbon Bond 5 (CB05) gaseous-phase chemistry mechanism (Sarwar et al., 2008) with Euler backward iterative (EBI) solver and the AERO4 aerosol mechanism (Binkowski and Roselle, 2002). The CB05 mechanism used here included mercury gaseous reactions with $\mathrm{O}_{3}, \mathrm{OH}$, $\mathrm{H}_{2} \mathrm{O}_{2}$ and $\mathrm{Cl}_{2}$ as described by Lin and Tao (2003). The meteorological fields used in CMAQ-Hg were provided by the Weather Research and Forecasting (WRF v3.2) model. The Meteorology-Chemistry Interface Processor (MCIP v3.6) processed the WRF outputs to the CMAQ-Hg model-ready format and dry deposition velocities of GEM and GOM were calculated. The process analysis (PA) technique is an advanced diagnostic method implemented in CMAQ. It provides hourly integrated process rates to quantify the changes in concentration from each of the scientific processes in the 


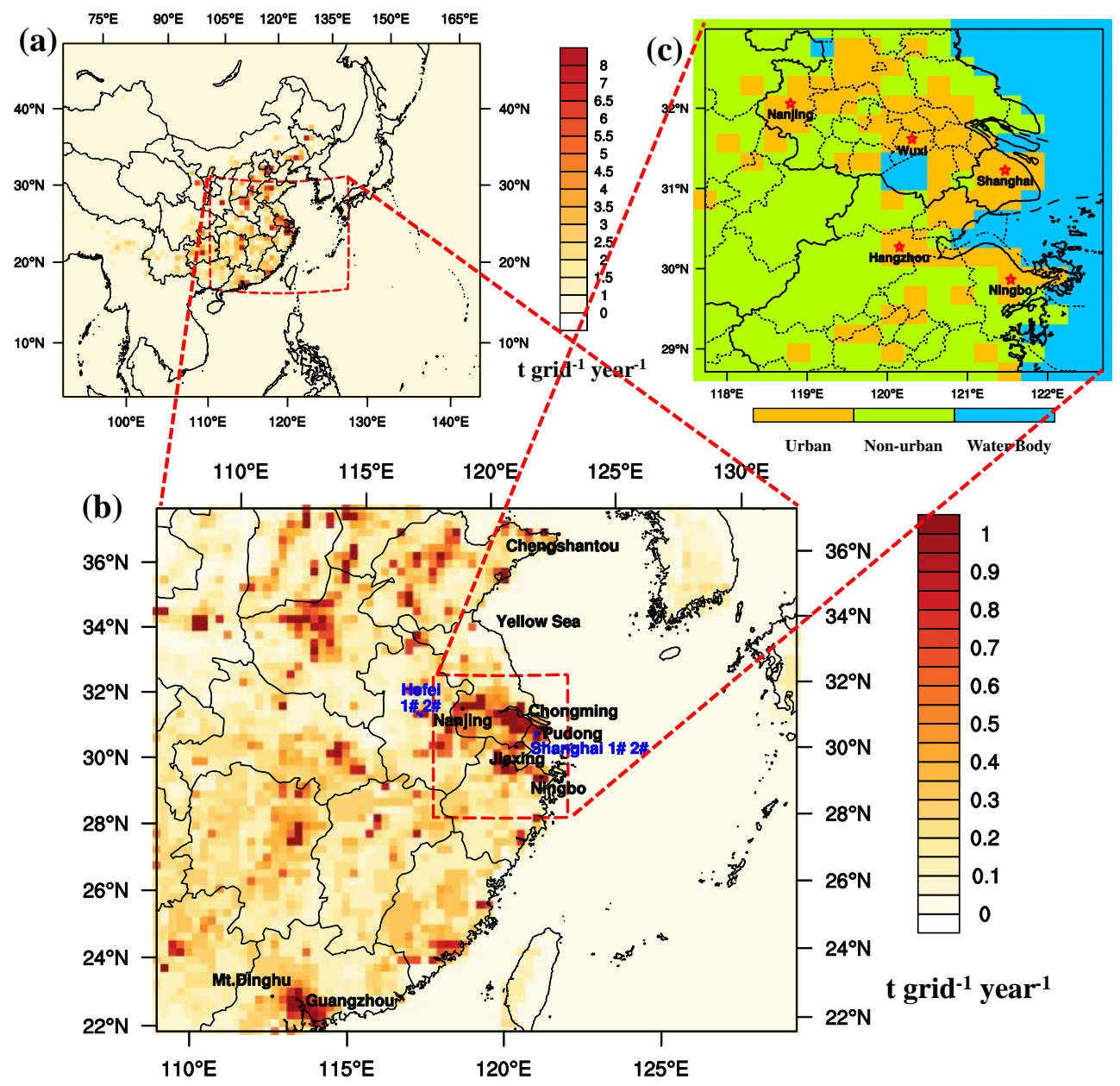

Figure 1. Model domains: (a) domain 1 with annual total mercury emission, (b) domain 2 with annual total mercury emission, and (c) Yangtze River delta (YRD) area with land use category.

mass conservation equations being solved for each mercury species. During this simulation, the contributions from the following physical and chemical processes were calculated: emissions of mercury species (EMIS), net gas-phase chemical production/loss (CHEM), horizontal advection (HADV), vertical advection (ZADV), horizontal diffusion (HDIF), vertical diffusion (VDIF), dry deposition (DDEP), cloud processes (CLDS, including cloud attenuation of photolytic rates, convective and non-convective mixing and scavenging by clouds, aqueous-phase chemistry, and wet deposition), and aerosol processes (AERO, including thermodynamic equilibrium and dynamics such as homogeneous nucleation, condensation/evaporation, and coagulation) (Liu and Zhang, 2013).

\subsection{Emission inventory}

Both anthropogenic and natural emission inventories of mercury were employed in our simulation with CMAQ-Hg. Emissions from natural sources (NAT) including vegetation, soil surface and water bodies were based on the estimates by Shetty et al. (2008). GEM is the only species emitted from natural sources. Secondary emissions that resulted from deposited mercury transformed to GEM and re-emitted to the atmosphere from soil and water were also considered. Anthropogenic mercury emissions in China were prepared following the approaches of Wang et al. (2014), which were updated to 2007 (Fig. 1a). The inventory data were not consistent with our modeling period but represented the most updated data at the time when this study was conducted. The monthly variation of anthropogenic sources was based on the monthly energy consumption and product yields published in the Chinese yearbook of provincial diversity. The ratios of three mercury species released were varied according to many factors like coal produced in different provinces, mercury content in coal consumed, different boiler types and removal efficiencies and different combinations of atmosphere pollution control devices (Wang et al., 2014). The total anthropogenic mercury sources (ANTH) in China were classified into six categories for source apportionment: (1) emis- 

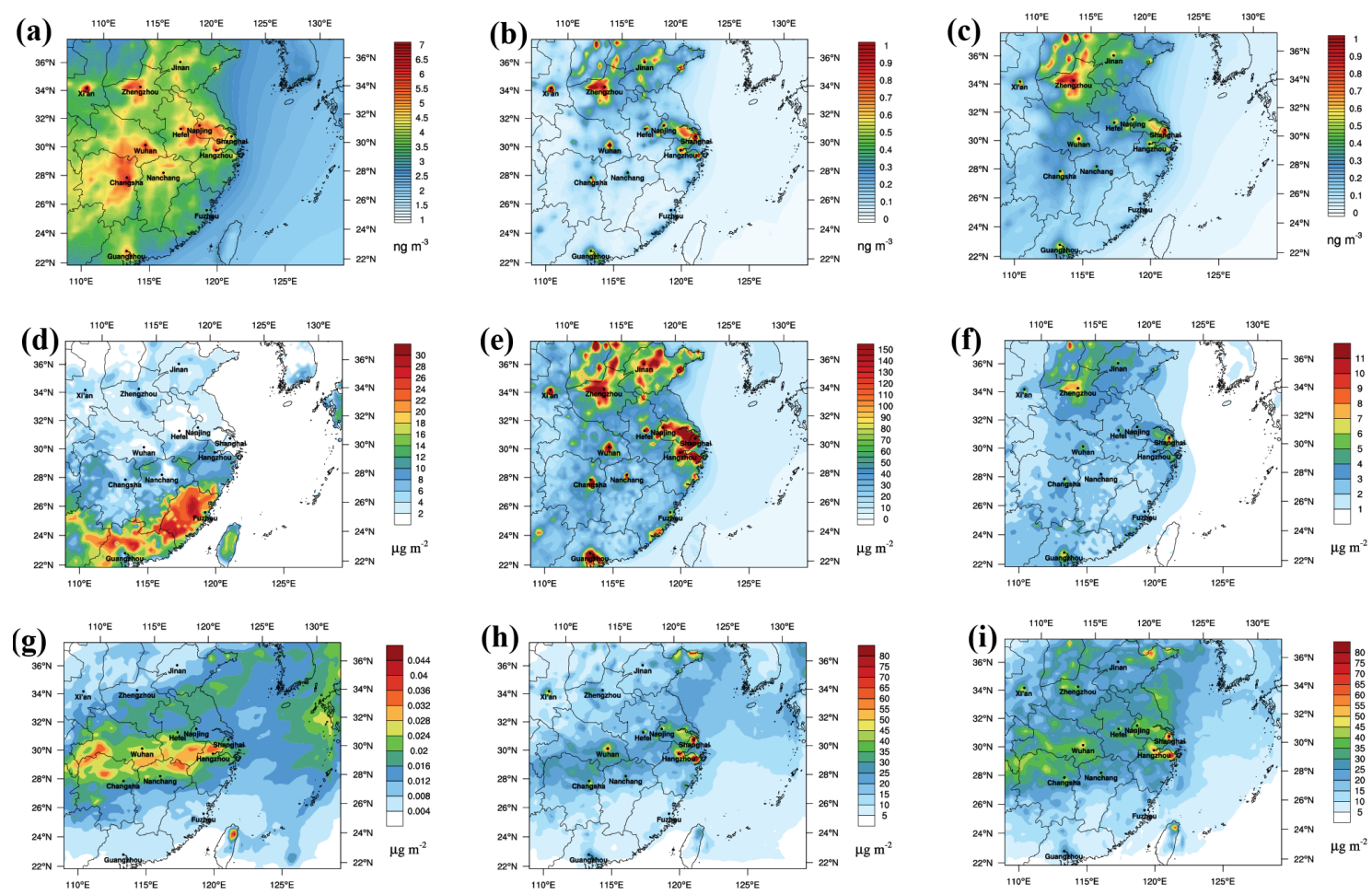

Figure 2. Simulated annual average concentration of (a) GEM, (b) GOM and (c) PBM; annual dry deposition of (d) GEM, (e) GOM and (f) PBM; and dry deposition of (g) GEM, (h) GOM and (i) PBM in eastern China in 2011.

sions from cement production (CEM); (2) emissions from domestic life (DOM), which includes waste incineration; domestic coal burning and application of battery and fluorescent lighting; (3) emissions from industrial boilers (IND) including boilers used for collective heating in North China during winter; (4) emissions from metal production (MET) including zinc smelters, lead smelters, copper smelters, iron production, mercury production and gold production; (5) emissions from coal-fired power plants (PP), which were all treated as large point sources in our simulation; and (6) emissions from traffic (TRA). Table 1 summarizes the emission inventory for China (land area in the outermost model domain) in 2007. The annual total anthropogenic emissions amount to $638 \mathrm{Mg} \mathrm{yr}^{-1}$ which was comparable to natural emissions of $551 \mathrm{Mg} \mathrm{yr}^{-1}$. The average speciation of anthropogenic emissions is as follows: GEM $49.5 \%$, GOM $38.4 \%$, and PBM $12.1 \%$.

\subsection{Model domain and scenarios}

The modeling period covers 1 year from 20 December 2010 to 31 December 2011 including an 11-day spin-up period. Two nested domains were used for the CMAQ-Hg model. The first domain (D01, Fig. 1a) covers most of China and some other parts of Asia with $85 \times 72$ horizontal grid cells at a spatial resolution of $81 \mathrm{~km} \times 81 \mathrm{~km}$. The initial and boundary conditions for D01 modeling were extracted from GEOS-
Chem global simulation results. The nested domain (D02, Fig. 1b) was defined over the eastern China area, which is the focus of this study. D02 contains $82 \times 67$ horizontal grids with a spatial resolution of $27 \mathrm{~km} \times 27 \mathrm{~km}$. There were 27 vertical layers with a top layer pressure of $100 \mathrm{hPa}$ for both domains. The Yangtze River delta (YRD; Fig. 1c) is one of the most industrialized and urbanized regions in eastern China and mercury pollution has become a problem of increasing concern; thus, the YRD was chosen for process analysis. Figure 1c showed the land use in the YRD which was divided into three categories: urban, non-urban and water body. A comparison was made of characteristics of processes influencing atmospheric mercury species in urban and non-urban areas.

Nine emission scenarios in China were considered in order to understand the relative importance of different emission sources to atmospheric mercury concentration and deposition. The base case (BASE) was run with both natural and all anthropogenic sources mentioned above. Seven sensitivity studies (C1-C7) were designed with one of the seven source sectors (i.e., NAT, CEM, DOM, IND, MET, PP and TRA) excluded in each study. In addition, the boundary conditions (BCs) were set to zero (C8). Subtracting the results of $\mathrm{C} 1-\mathrm{C} 8$ from the BASE case yields an estimate of mercury associated with these mercury sources. 
Table 1. Summary of mercury emissions in the model domain 1.

\begin{tabular}{lrrrr}
\hline & GEM $\left(\mathrm{Mg} \mathrm{yr}^{-1}\right)$ & GOM $\left(\mathrm{Mg} \mathrm{yr}^{-1}\right)$ & PBM $\left(\mathrm{Mg} \mathrm{yr}^{-1}\right)$ & Total $_{\left(\mathrm{Mg} \mathrm{yr}^{-1}\right)}$ \\
\hline Natural & 551 & 0 & 0 & 551 \\
Anthropogenic & 316 & 245 & 77 & 638 \\
CEM & 69.0 & 12.9 & 4.3 & 86.2 \\
DOM & 6.4 & 9.2 & 24.7 & 40.3 \\
IND & 34.1 & 149.0 & 27.2 & 210.3 \\
MET & 100.6 & 30.1 & 5.3 & 136.0 \\
PP & 84.2 & 38.1 & 1.3 & 123.6 \\
TRA & 8.1 & 5.9 & 14.0 & 28.0 \\
\hline Total & 867 & 245 & 77 & 1189 \\
\hline
\end{tabular}

\section{Results and discussion}

\subsection{Model validation}

The spatial distribution of annual average concentrations and annual total depositions of GEM, GOM and PBM simulated in BASE are shown in Fig. 2. The predicted annual average concentrations of GEM, GOM and PBM were in the ranges of $1.8-8.4,0.015-1.5$ and $0.017-1.3 \mathrm{ng} \mathrm{m}^{-3}$. On average, GEM constituted $92.8 \%$ of the total atmospheric mercury with the contribution going down to a minimum of $58.6 \%$ near large anthropogenic sources (Fig. 2a). The concentrations of GOM and PBM were typically higher at locations of large cities due to the greater anthropogenic emissions there and decreased rapidly away from source locations because of their relatively shorter atmospheric lifetimes (Fig. 2b, c). The total mercury deposition was $65.3 \mu \mathrm{g} \mathrm{m}^{-2} \mathrm{yr}^{-1}$, with $34.3 \mu \mathrm{g} \mathrm{m}^{-2} \mathrm{yr}^{-1}$ of total dry deposition and $31.0 \mu \mathrm{g} \mathrm{m}^{-2} \mathrm{yr}^{-1}$ of total wet deposition. The dry deposition of GEM was $4.26 \mu \mathrm{g} \mathrm{m}^{-2} \mathrm{yr}^{-1}$, on average, with the larger deposition in the southern part of D02 due to the larger dry deposition velocity of GEM there (Fig. 2d). GOM contributed $28.2 \mu \mathrm{g} \mathrm{m}^{-2} \mathrm{yr}^{-1}$ to total dry deposition with a

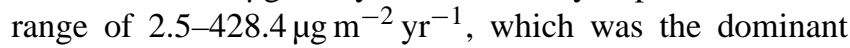
fraction of mercury dry deposition. The distribution of the dry deposition of GOM and PBM resembled the spatial pattern of urban areas in eastern China as a result of high concentrations of GOM and PBM there, especially showing the elevated deposition in the eastern (i.e., YRD) and northern parts of D02 (Fig. 2e, f). The wet deposition was dominated by PBM $(56.5 \%)$ followed by GOM (43.4\%). The distribution of wet deposition was affected by the spatial pattern of concentration and precipitation (Fig. 2h, i). The wet deposition of GEM was negligible due to its low solubility in water (Fig. 2g).

The results from the base case were compared to observations to give a preliminary evaluation of model performance. As long-term mercury measurements in eastern China are very limited, all available measurement results (listed in Zhu et al., 2012, 2014) in eastern China were used to assess model skill; i.e., TGM concentrations were obtained in nine sites, PBM concentrations were obtained in five sites and wet deposition was only observed in Nanjing. The locations of these sites are given in Fig. 1b. Although the analysis in the following sections uses the model results for 2011, the same time frame with observations reported was simulated for model validation. Figure 3 shows the comparison between averaged measurements and CMAQ results during homologous months. For most sites - such as Chengshantou (Ci et al., 2011a), Ningbo (Nguyen et al., 2011), Guangzhou (Chen et al., 2013), Jiaxing (Wang et al., 2007), Mt. Dinghu (Chen et al., 2013), Chongming (Dou et al., 2013), Nanjing (Zhu et al., 2012) and the Yellow Sea (Ci et al, 2011b) - the simulated TGM is quite consistent with observations with a relative bias of 4-28\% (Fig. 3a). In comparison, modeled TGM concentrations in Pudong were $\sim 51 \%$ overestimated. The site in Pudong (Friedli et al., 2011) was located at a costal urban area with less than 1 month of measurement data. The short duration of this measurement and unexpected complex emission and meteorological condition may be responsible for the larger bias. The correlation coefficient between the averaged observed and simulated TGM concentration in all sites was 0.85 . The model can reproduce the averaged TGM concentration in most areas of eastern China, but the model results have a smaller variability especially in urban sites like Nanjing where the standard deviation of the simulation result was $4.86 \mathrm{ng} \mathrm{m}^{-3}$ lower than that observed. This is expected to be the incapability of the model to capture emission plumes and predict the transient peaks observed in urban sites because of the $27 \mathrm{~km}$ grid cell resolution and assumption of instantaneous emission dilution in grid cells (Pongprueksa et al., 2008). As seen in Fig. 3b, the model results were also comparable to PBM concentrations observed in Nanjing (Zhu et al., 2014), Shanghai (Xiu et al., 2009) and Hefei (Wang, 2010). The PBM concentration in Nanjing was underestimated by $60 \%$, which may be because the location of the observation site in Nanjing is in the central urban area with much higher particle concentration compared to the averaged concentration in the simulation grid cell. The scarcity of mercury deposition measurement in eastern China limited the evaluation 

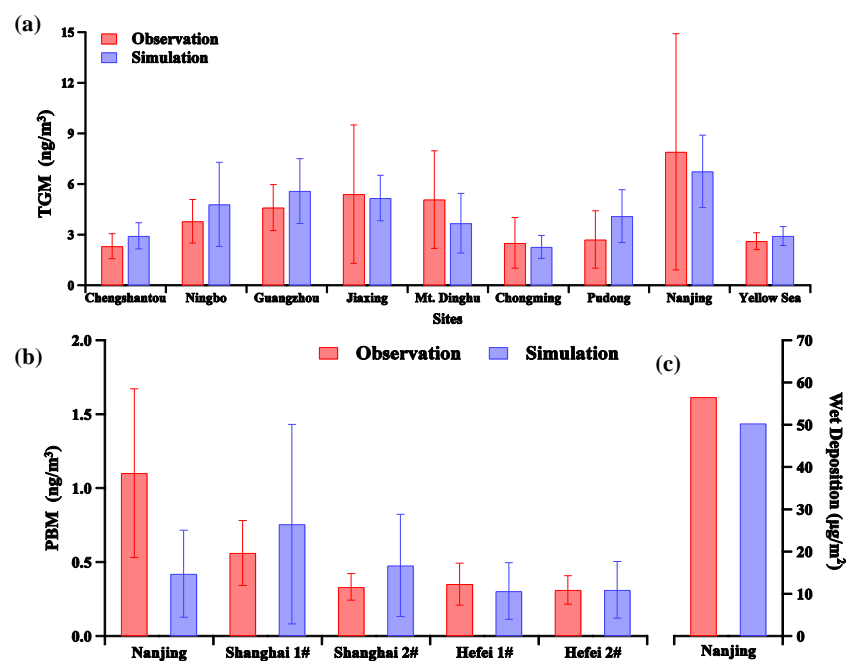

Figure 3. Comparison between simulated results and measurements in sites for (a) TGM concentration, (b) PBM concentration and (c) wet deposition.

of model performance for mercury deposition. Our model result agrees reasonably well with mercury wet deposition measurement results from the Nanjing site during 9 months in 2011 (Zhu et al., 2014), with a $6.3 \mu \mathrm{g} \mathrm{m}^{-2}$ underestimation which was caused by $232.8 \mathrm{~mm}$ ( $21.8 \%$ to total) of less precipitation and lower PBM concentration predicted in urban areas. Overall, our simulation did well in reflecting the levels and deposition of atmospheric mercury in eastern China and is suitable for further analysis of source apportionment.

\subsection{Source apportionment}

\subsubsection{Natural sources (NAT)}

Figures 4 and 5 summarize annual and seasonal relative contributions of different source sectors to atmospheric mercury concentration and deposition in eastern China (land area in D02). Annual total mercury emissions from natural sources were close to those from anthropogenic sources. Because all natural emissions are in the form of GEM, this sector is responsible for $63.6 \%$ of the total annual GEM emission in China. The result was that natural sources are the largest contributor to atmospheric GEM concentration (36.6\% in annual average). Due to significant seasonal variation of GEM emission from NAT, the contributions from NAT to GEM varied between $52.2 \%$ in summer and $15.0 \%$ in winter. NAT were much more important for GEM concentrations in summer with a factor of 3.3 to the contribution from ANTH $(15.9 \%)$. Though GEM was not the key species for mercury deposition, NAT were still an important contribution to wet and dry deposition in summer with 28.5 and $24.3 \%$, respectively. The higher emissions from NAT and the increased photochemical activities in summer led to a greater degree of GEM oxidation to GOM and transformation to PBM, which

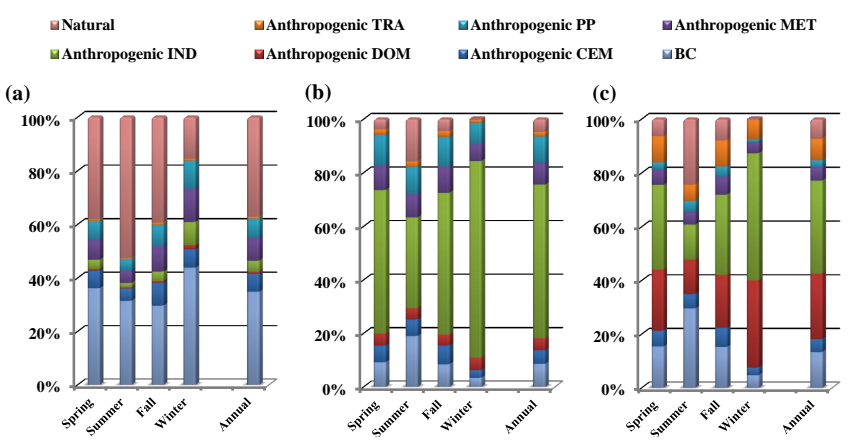

Figure 4. Source contributions to seasonal and annual averaged (a) GEM, (b) GOM and (c) PBM concentrations.

(a)

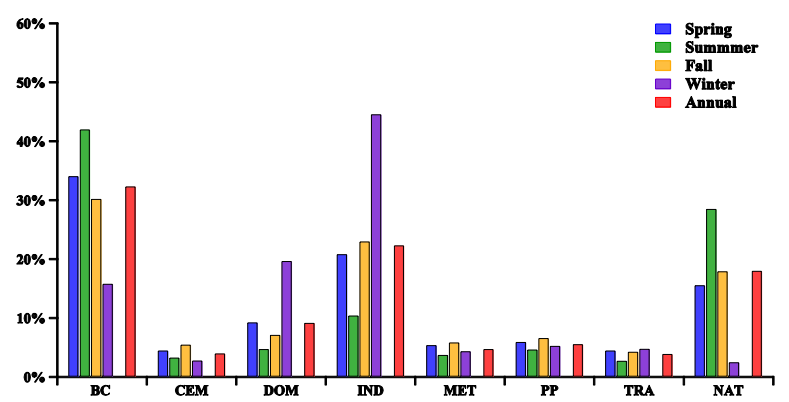

(b)

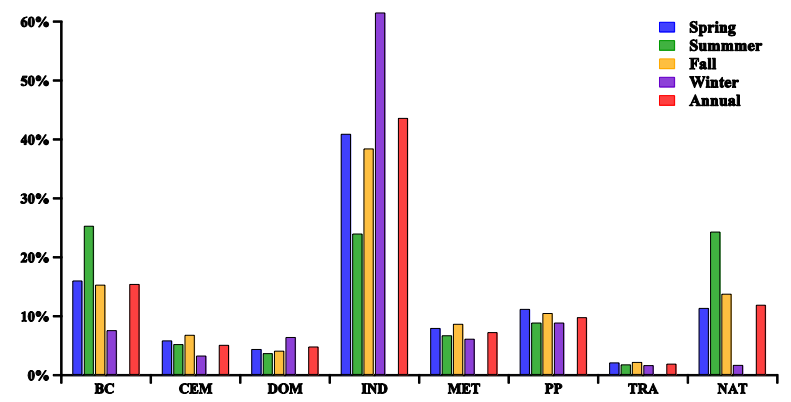

Figure 5. Source contributions to seasonal and annual mercury (a) wet and (b) dry depositions.

contributed $15.7 \%$ of GOM and $24.2 \%$ of PBM in summer. In contrast, NAT contribute little to GOM concentration $(0.2 \%)$, PBM concentration $(0.3 \%)$ and deposition $(2.4 \%$ to wet deposition and $1.7 \%$ to dry deposition) in winter. Therefore, during winter, ANTH had a much larger impact on atmospheric mercury concentration and deposition. The effect from NAT decreased from south to north in the mainland of D02, correlating with air temperature. There was no obvious difference between the quantities contributed from NAT to urban and rural areas but the relative contribution to urban areas was lower due to higher emissions and thus concentration and deposition in urban areas. 


\subsubsection{Cement production (CEM)}

In 2011, anthropogenic sources emitted $638 \mathrm{Mg}$ of mercury, which was a little more than that from natural sources $\left(551 \mathrm{Mg} \mathrm{yr}^{-1}\right)$. However, unlike natural sources, mercury from ANTH includes GEM, GOM and PBM. The quantity and speciation of mercury released from six anthropogenic source categories were quite different. This leads to different impacts on the spatial and temporal distribution of atmospheric mercury concentration and deposition.

Total mercury emission from CEM is responsible for $13.5 \%$ of the total anthropogenic emissions and $\sim 80 \%$ of the mercury from CEM was in the form of GEM. CEM contributed $6.6 \%$ to the total annual GEM concentration which was $23.9 \%$ of the total contribution from all anthropogenic sources. The impact on GOM and PBM concentrations from CEM was much lower than that of most other anthropogenic sources. As GEM had little impact on mercury deposition, CEM changed wet and dry deposition by only 4.0 and $5.1 \%$, respectively. The seasonal variation of the contribution from CEM was negligible because of the production of cement was relatively constant over the whole year. CEM affected the GEM concentration in the eastern coastal area most evidently by up to $20 \%$ because of the high emissions from cement plants in the Shandong, Jiangsu and Zhejiang provinces which are responsible for $\sim 26 \%$ of the total emissions from CEM in China.

\subsubsection{Industrial boilers (IND)}

Emissions of total mercury from IND made up $32.9 \%$ of all anthropogenic emissions in China. Thus, it is the most important anthropogenic source. Moreover, $70.8 \%$ of the total mercury emitted from IND was GOM, which makes up $60.8 \%$ of the total GOM emissions in China. IND were also the largest source of PBM in China. Owing to the large quantity of GOM and PBM which can deposit near the emission sources through dry and wet deposition, IND make the largest contribution to mercury deposition with 22.3 and $43.6 \%$ of annual wet and dry deposition, corresponding to 57.5 and $34.4 \%$ of the annual averaged GOM and PBM concentrations. Especially in winter, IND dominated the GOM concentration and mercury dry deposition with the contribution reaching 73.3 and $63.9 \%$, respectively, as a result of large-scale collective heating in northern China. The measurement by Zhang et al. (2013) also indicated the boilers play an important role in the rise of mercury concentrations in winter in rural Beijing.

\subsubsection{Power plants (PP)}

Emissions from PP were another important sector and they were treated as point sources in the model. GEM and GOM are the main species emitted from PP with percentages of 68.1 and $30.8 \%$ and, in contrast, with only $1.1 \%$ of PBM.

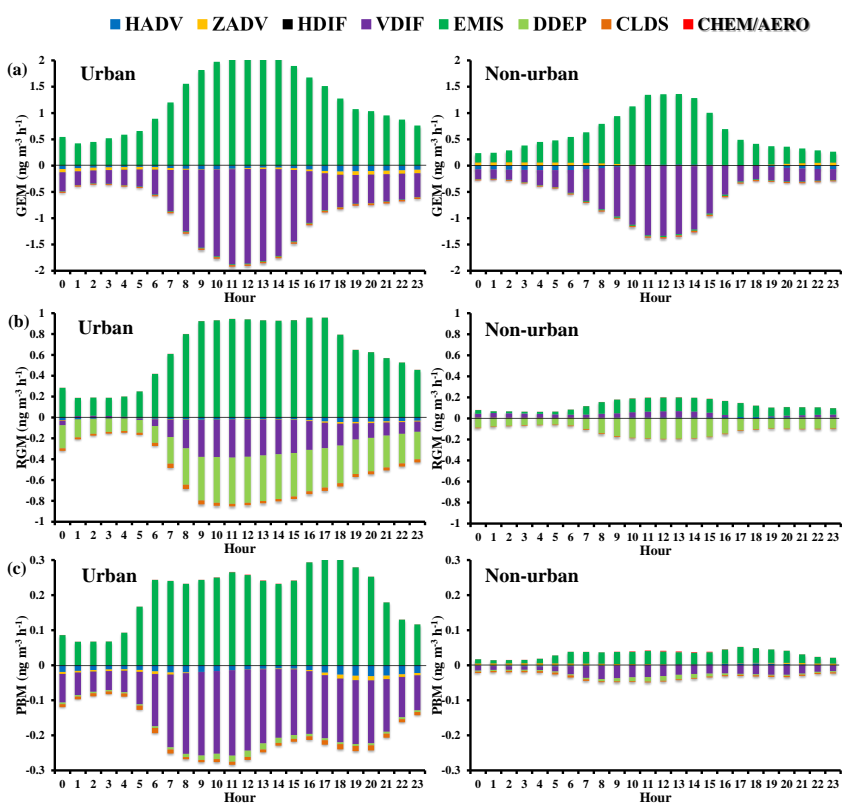

Figure 6. Diurnal variations of processes of (a) GEM, (b) GOM and (c) PBM in urban and non-urban areas.

PP were the smallest contributor $(2.5 \%)$ to PBM. However, PP were the second largest contributor to GEM and GOM concentration (7.1 and 9.6\%, respectively) among all anthropogenic sources, although its contribution to GOM concentration was much lower than the largest GOM emissions from IND. Emissions from PP were responsible for 5.5 and $9.8 \%$ of wet and dry deposition, which resulted from significant impacts on GOM concentrations. There were many larger coal-fired power plants with capacities larger than $1000 \mathrm{MW}$ in the YRD. Because of this, obviously, higher emission intensity from PP led to a much higher influence on atmospheric mercury pollution in the YRD with an annual averaged contribution to TGM of up to $1 \mathrm{ng} \mathrm{m}^{-3}$ (> 20\%).

\subsubsection{Metal production (MET)}

MET was the largest anthropogenic source of GEM, accounting for $31.8 \%$ of the anthropogenically emitted GEM. As this sector includes manufacturers and smelters of various iron and non-iron metals, the content of mercury from MET varied greatly depending on production process and the mercury content in raw materials. The speciation factors ranged from 65 to $89 \%$ for GEM, 6 to $30 \%$ for GOM, and 0 to $17 \%$ for PBM. Overall, MET contributed 8.4, 8.2 and 5.0\% to GEM, GOM and PBM concentrations and was responsible for 4.7 and $7.2 \%$ of the annual wet and dry deposition in eastern China, respectively. Although MET was distributed widely in eastern China, the effects of emissions from MET were greatest in Shaanxi Province due to high mercury concentrations in zinc ore and some small-scale plants with poor mercury control devices (Wu et al., 2012). 

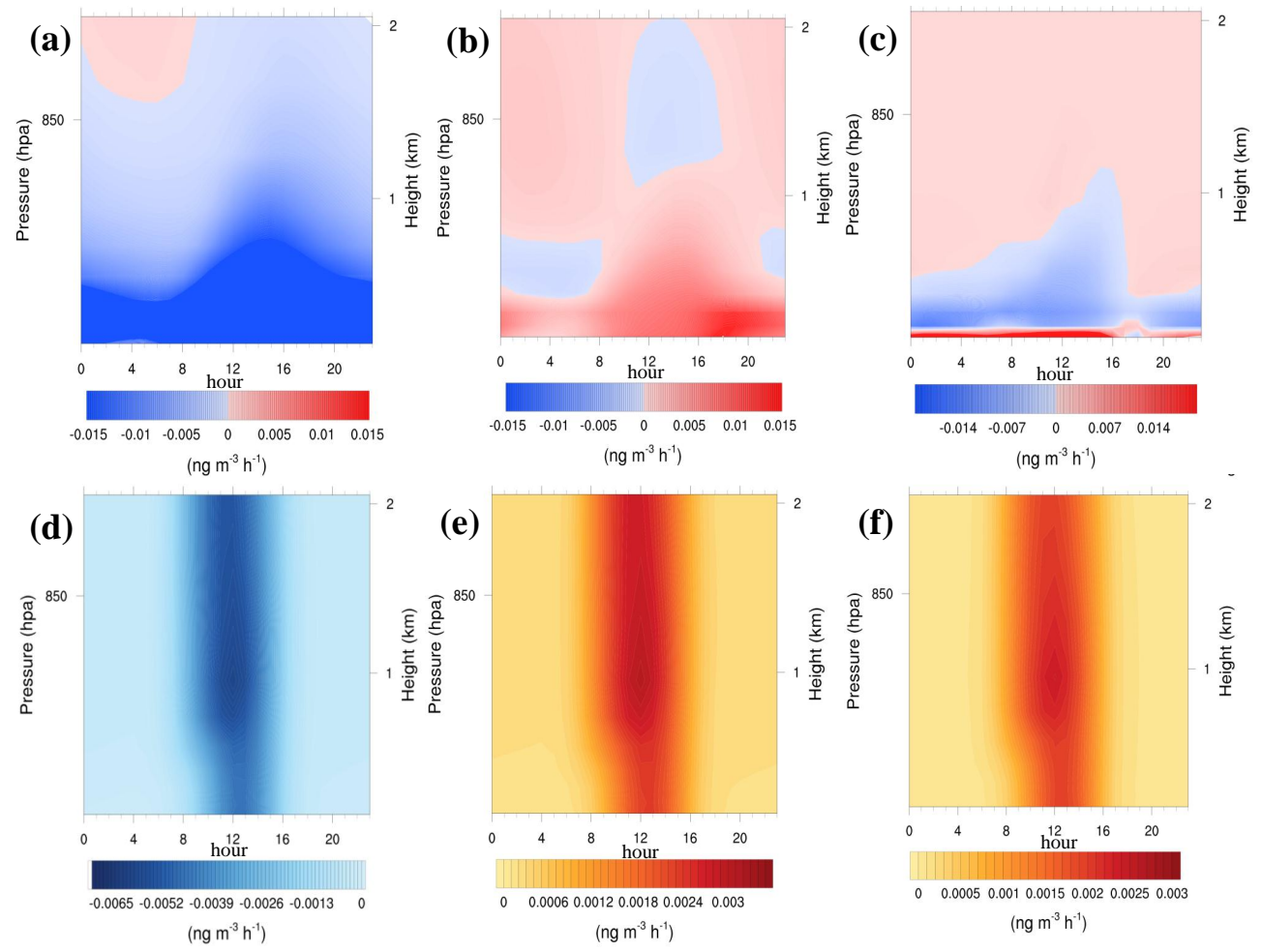

Figure 7. Profile of the contribution of (a) HADV to GOM in urban areas and (b) HADV to GOM, (c) VDIF to GOM, (d) CHEM to GEM, (e) CHEM to GOM and (f) AERO to PBM in non-urban areas.

\subsubsection{Domestic life (DOM) and traffic (TRA) emissions}

DOM $(6.3 \%)$ and TRA $(4.4 \%)$ emissions were the small fraction of anthropogenic sources. They both hardly affected GEM concentrations with a contribution of less than $1 \%$ and had little influence on GOM concentrations ( $4.4 \%$ from DOM and $1.8 \%$ from TRA). However, over $50 \%$ of total PBM emissions came from DOM and TRA and they increased the annual averaged PBM concentration by 24.4 and $8.0 \%$, respectively. As PBM was the main component in mercury wet deposition, DOM was the most important anthropogenic contributor $(9.1 \%)$ to wet deposition except IND $(22.3 \%)$. In contrast, DOM and TRA were the two smallest contributors to mercury dry deposition with 4.8 and $1.9 \%$ because GOM was the dominant contributor to mercury dry deposition. The distribution of emissions from TRA was very heterogeneous with the majority emitted in large cities. In spite of the lower total emissions from TRA, the impacts on PBM concentrations and deposition were much higher in and around the province capitals and other large cities by a factor of 2-20 compared to rural areas.

\subsubsection{Long-range transport}

The impacts of boundary conditions (BCs) were also significant for mercury pollution in eastern China, which indicates the contribution of mercury emissions from other source regions. GEM can be transported far beyond the regions where it is emitted and it is hardly deposited. Therefore, GEM in the global mercury pool affected the concentration in China, evidently suggested by our simulation result with up to $34.3 \%$ of the annual averaged GEM concentration from BCs. However, BCs have little effect on GOM concentration with a contribution of only $8.6 \%$ because of its relatively short lifetime. The contribution to GEM concentrations from BCs was largest in winter, while the contribution to GOM concentration was the lowest then because of relatively weaker emissions of GEM and stronger emissions of GOM in China during winter. BCs influenced the annual averaged PBM concentration by $13.3 \%$ due to the low dry deposition velocity of fine-size PBM. As PBM was removed mainly by wet deposition, BCs contributed $32.3 \%$ to annual wet deposition of mercury in China. In comparison, only $15.4 \%$ of annual dry deposition was linked to BCs, owing to the small contribution to GOM. Lin et al. (2012) estimated that $89.1 \%$ of mercury dry deposition and $93.2 \%$ of mercury wet deposition in contiguous US regions are caused by global sources, which is much higher than the ratio estimated for eastern China in this study. One of the reasons for this is the much higher lo- 
cal anthropogenic emission of mercury in China. Moreover, the anthropogenic sources out of China were not defined accurately. The underestimation of emission sources from other countries would lead to lower contributions from BCs to eastern China.

\subsection{Process analysis}

Figure 2 depicts the simulated concentration and deposition of mercury species during 2011 in eastern China, which indicated that the YRD is one of most polluted areas with high mercury concentration and deposition. Also, the YRD is one of the most active areas of human activity in China. Therefore, the YRD area, which is shown in Fig. 1c, was chosen to study the influence of each physical and chemical process implemented in CMAQ on atmospheric mercury. The area was divided into urban, non-urban and water bodies depending on the predominant land use. The area with an urban coefficient of land use of more than $10 \%$ was defined as an urban area in this study. Comparisons of the contribution of each process to urban and non-urban mercury concentrations were studied.

\subsubsection{Controlling processes}

The annual averaged diurnal variations of the contribution from nine processes which included HADV, ZADV, HDIF, VDIF, EMIS, DDEP, CLDS and gas- and aerosol-phase chemistry (CHEM/AERO) to the concentration of GEM, GOM and PBM in the near-surface layer (the first layer in the model was about $50 \mathrm{~m}$ ) in urban and non-urban areas of the YRD are shown in Fig. 6. The results indicate that two major processes dominate surface GEM concentration, namely EMIS and VDIF, and their contributions were comparable in urban and non-urban areas (Fig. 6a). The contributions of EMIS and VDIF to the change of GEM concentration were noticeably temporally variable with much higher values at midday. Their contribution at midnight was $>5$ times larger than those at night and they tended to compensate each other all of the time. The effect of EMIS increased gradually in the daytime along with the increase of temperature and solar radiation, which led to higher emission from NAT. Anthropogenic activity and production are more active during the daytime, which raised the emissions of mercury especially in urban areas. EMIS was the only process with a positive contribution to GEM concentration in urban areas, with annual average of $1.26 \mathrm{ng} \mathrm{m}^{-3} \mathrm{~h}^{-1}$, and all other processes played the opposite role. However, HADV and ZADV could contribute to both gains and losses of GEM in non-urban areas throughout the day. Advection processes had a more significant influence on surface GEM concentration during the evening and early morning in both urban and non-urban areas but ZADV had the opposite effect with a positive influence in non-urban areas and a negative influence in urban areas at night possibly because of the strong heat island circulation.
Processes of DDEP and CLDS made small contributions to the loss of GEM. On average, they reduced the concentration of GEM by about $0.8 \mathrm{ng} \mathrm{m}^{-3}$ day $^{-1}$ in urban and non-urban areas.

Unlike GEM, the contributions from different processes on surface GOM and PBM concentrations were much lower in non-urban than that in urban areas due to lower emissions of GOM and PBM in non-urban areas (Fig. 6b, c). EMIS and VDIF were also the dominant processes to change the surface GOM and PBM concentrations similar to those of GEM. However, DDEP and CLDS were two additional dominant processes influencing GOM and PBM because of higher dry deposition velocity and reactivity of GOM and PBM. Particularly for GOM, DDEP was the most important removal process, with the surface concentrations of 7.3 and $2.9 \mathrm{ng} \mathrm{m}^{-3}$ reduced in urban and non-urban areas, respectively, in 1 day. The local dry deposition of GOM was about $48 \%$ of local emissions in urban areas while that in non-urban areas was $42 \%$ larger than local emissions which were affected by the emissions from nearby urban areas. In addition, VDIF could contribute to gains of surface GOM in non-urban areas in most hours, which indicated higher GOM concentrations in the free troposphere. Figure 7 displays annual averaged diurnal profiles of the variation of HADV, VDIF, CHEM and AERO below $2 \mathrm{~km}$. HADV played an almost opposite role in changing GOM concentration within the boundary layer in urban and non-urban areas (Fig. 7a, b), but the trend of temporal variation and magnitude of contributions were about the same; it further indicated the transport of GOM from urban to non-urban areas which was the main source of GOM in the upper air of non-urban areas. The contribution of VDIF to the GOM concentration is displayed in Fig. 7c. More horizontally advected GOM aloft was mixed downwards to ground levels along with the increase of boundary layer height with the largest contribution of $\sim 0.06 \mathrm{ng} \mathrm{m}^{-3} \mathrm{~h}^{-1}$ at noon, which was why the contribution from VDIF was positive in the surface layer and negative at higher altitudes. CHEM was another contributor to the accumulation of GOM as well as AERO to PBM in the upper air, though CHEM and AERO seemed to be negligible in changing GOM and PBM concentrations in the surface layer. Figure 7d-f show that the contributions of CHEM and AERO were much higher in the upper layers than that at the surface especially around noon since most of mercury chemical reactions rely on solar radiation. CHEM and AERO are the most important processes to transform GEM to GOM and PBM in the atmosphere. Within $2 \mathrm{~km}$ of non-urban areas, the column concentration of GOM was increased by $41.9 \mathrm{ng} \mathrm{m}^{-2}$ owing to the transformation of GEM through CHEM and the column concentration of PBM increased by $29.1 \mathrm{ng} \mathrm{m}^{-2}$ through AERO in 1 day. The increases in GOM and PBM through CHEM and AERO in urban areas were about $13 \%$ less than in non-urban areas. A combination of HADV, ZADV, VDIF, DDEP and CLDS tended to cancel out the gain of PBM from EMIS and AERO in urban areas. In 
spite of most decreases from VDIF in urban areas, the other four processes also make a $21 \%$ contribution to remove surface PBM. However, both of HADV and ZADV transported PBM to the surface layer in non-urban areas. The strongest increase of surface PBM occurred in the afternoon, 16:0018:00 h, due to higher emission rates of DOM and TRA, which were the most important sources for PBM while most of the decrease occurred in the morning, between 09:00 and 11:00 $\mathrm{h}$ because the VDIF process was most effective then. In urban areas, the contribution from DDEP to PBM was $20 \%$ less than that from CLDS. In comparison, DDEP contributed $57 \%$ more than CLDS to the loss of surface PBM in nonurban areas. The contribution from HDIF was negligible for all of GEM, GOM and PBM concentrations.

\subsubsection{Impacts of sources on processes}

Different mercury emission sources had different influences on processes due to their different distribution and intensity. The contributions of natural sources and various anthropogenic sources to GEM processes in urban and nonurban areas of the YRD are compared in Fig. 8. Various anthropogenic sources, especially CEM and PP, were the main sources leading to GEM advection out of urban areas at $0.077 \mathrm{ng} \mathrm{m}^{-3} \mathrm{~h}^{-1}$ by HADV while natural sources mainly caused GEM to be horizontally transported away from nonurban areas with $0.021 \mathrm{ng} \mathrm{m}^{-3} \mathrm{~h}^{-1}$ (Fig. 8a). ANTH made a similar contribution to DDEP and CHEM of GEMin both non-urban and urban areas. In comparison, natural sources affected DDEP and CHEM of GEM $>110 \%$ in non-urban than in urban areas though emissions from NAT in non-urban areas only $38 \%$ more than in urban areas (Fig. 8d, e). Conversely, NAT caused comparable losses of GEM by VDIF in both areas and ANTH influenced VDIF of GEM in urban areas much more evidently (Fig. 8c). In the YRD, emissions of GEM mostly came from CEM and PP which contributed locally to GEM concentrations with 0.32 and $0.27 \mathrm{ng} \mathrm{m}^{-3} \mathrm{~h}^{-1}$ in urban areas. More than $80 \%$ of the GEM emissions in non-urban areas were emitted by natural sources (Fig. 8b). In total, local emissions in the YRD contributed $37.2 \%$ to the annual averaged GEM concentration in non-urban areas and $45.7 \%$ in urban areas.

Local emissions in the YRD were the primary source for GOM and PBM concentrations with a contribution of $74.8 \%(92.9 \%)$ to GOM concentration and $44.0 \%$ (66.0\%) to PBM concentration in non-urban (urban) areas. As GOM and PBM were the main constituents of mercury deposition, local emissions in the YRD contributed $65.1 \%(88.7 \%)$ to the annual mercury dry deposition and $37.3 \%(56.2 \%)$ to mercury wet deposition in non-urban (urban) areas of the YRD. Obviously, local emissions have a larger influence on mercury concentration and deposition in urban areas. However, local emissions also were the most important factor for mercury pollution in non-urban areas. Figures 9 and 10 show the contribution from different sources on the various

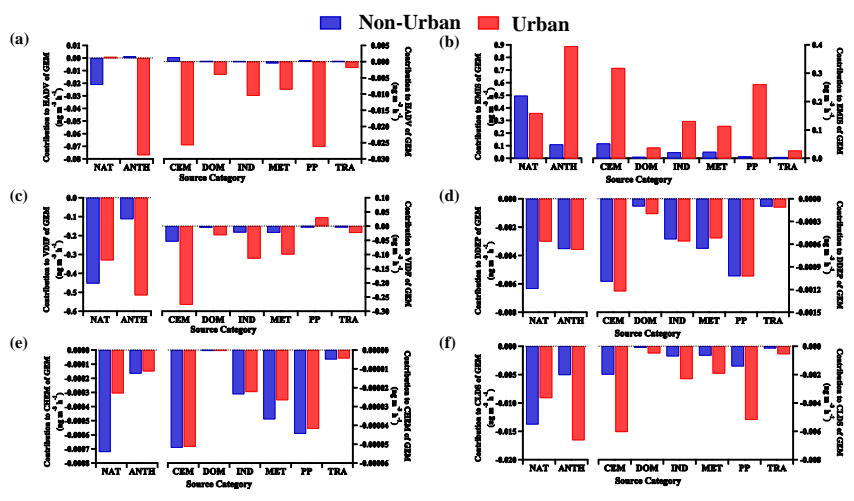

Figure 8. Impact of emission sources on (a) HADV, (b) EMIS, (c) VDIF, (d) DDEP, (e) CHEM and (f) CLDS processes of GEM.

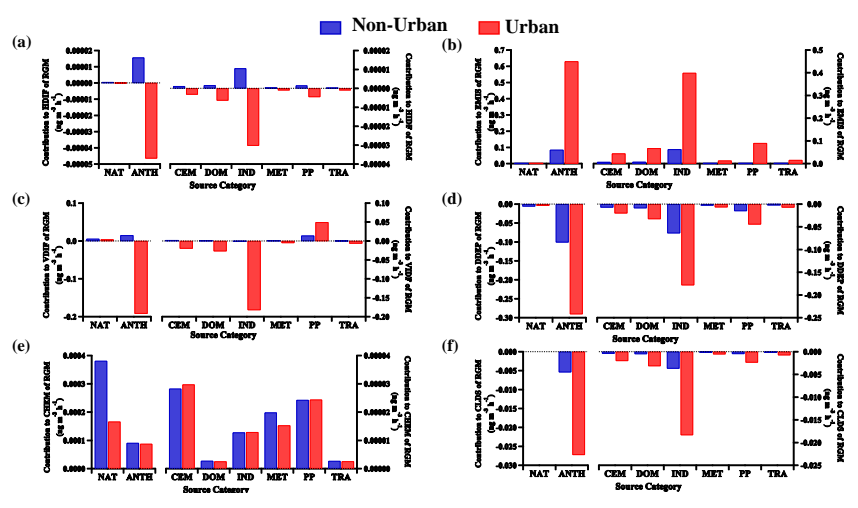

Figure 9. Impact of emission sources on (a) HADV, (b) EMIS, (c) VDIF, (d) DDEP, (e) CHEM and (f) CLDS processes of GOM.

processes of GOM and PBM in two areas. Natural sources only affected CHEM and AERO especially in non-urban areas compared to anthropogenic sources (Figs. 9e, 10e). IND were the largest contributor to all processes of GOM except for CHEM (Figs. 9) while DOM contributed most to all processes of PBM besides AERO (Fig. 10). All anthropogenic sources increased the outflow of GOM and PBM from urban areas and enhanced the inflow into non-urban areas. Moreover, the quantity of inflow in non-urban areas was directly proportional to the outflow in urban areas, which also indicates the influence of urban emissions on mercury pollution in non-urban areas via HADV (Figs. 9a, 10a). Figure 9c depicts that the effects of PP on VDIF of GOM were opposite to those of other anthropogenic sources. Emissions from PP increased the surface GOM concentration by VDIF, which was because the emissions from PP were mostly in the free troposphere and formed a large concentration center there. Most of the GOM at higher altitudes would be diffused to the surface in local urban areas and some would be transported to nonurban areas and then increase surface GOM concentrations there by VDIF. Due to the limited emissions of PBM from PP, the influence on VDIF of PBM from PP was negligible (Fig. 10c). 


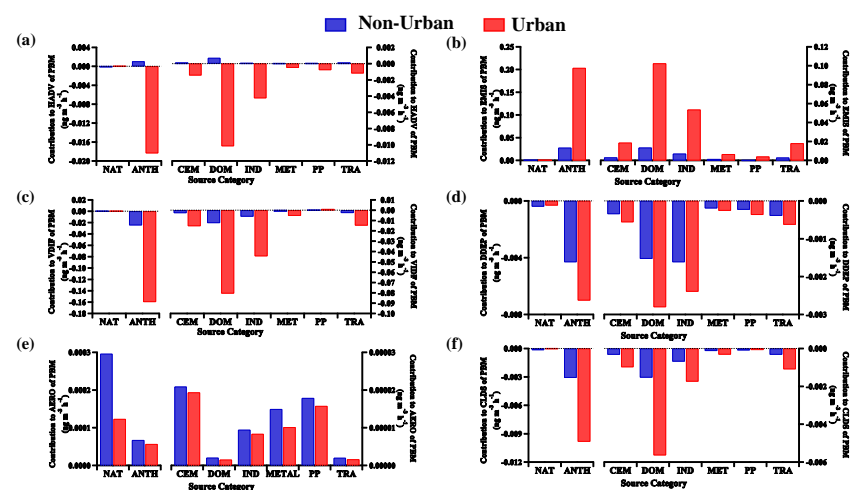

Figure 10. Impact of emission sources on (a) HADV, (b) EMIS, (c) VDIF, (d) DDEP, (e) CHEM and (f) CLDS processes of PBM.

\section{Conclusion}

The simulation of atmospheric mercury in eastern China was conducted using CMAQ-Hg with a grid resolution in a nested domain of $27 \mathrm{~km} \times 27 \mathrm{~km}$ to study source apportionment and process analysis. An updated mercury emission inventory for 2007 with anthropogenic emissions of $638 \mathrm{Mg} \mathrm{yr}^{-1}$ in China as well as emissions from natural sources of $551 \mathrm{Mg} \mathrm{yr}^{-1}$ was used for this simulation. The base model results were consistent with the measurements of atmospheric mercury including the concentrations of TGM and PBM as well as the wet deposition in most sites of eastern China.

Model results for source apportionment showed that natural emissions are the most important source for GEM concentration in eastern China with a contribution of $36.6 \%$. However natural sources were less important in winter than anthropogenic sources due to significant seasonal variation of emissions. Among the anthropogenic sources, MET and PP were largest contributors to GEM. For GOM and PBM, anthropogenic sources dominated the variation of concentration with contributions of 86.7 and $79.1 \%$ to the annual averaged concentrations. IND were responsible for $57.5 \%$ of the GOM concentration, on average, with the highest influence during winter time. IND also contributed significantly to PBM together with DOM sources and they accounted for $58.8 \%$ of annual averaged PBM. In total, 42.7 and $62.4 \%$ of wet and dry deposition of mercury in eastern China came from anthropogenic sources. Because of the large contribution to GOM and PBM, IND caused most of the most mercury deposition. Natural sources amounted to a quarter of wet and dry deposition in summer, owing to higher emissions and the increased photochemical oxidation to GOM and transformation to PBM during this season. The impact of mercury emitted from outside of China was also significant for mercury pollution in eastern China. This was indicated by a contribution of more than $30 \%$ from the model BCs to GEM concentration and wet deposition.
The influence of atmospheric processes on mercury concentration in the near-surface layer was analyzed in urban and non-urban areas of the YRD. Emissions and vertical diffusion affected surface GEM and PBM concentrations most and tended to compensate each other all the time in both urban and non-urban areas. However, dry deposition was the most important removal process for GOM with 7.3 and $2.9 \mathrm{ng} \mathrm{m}^{-3}$ deposited in urban and non-urban areas, respectively, on an average day. The variation of diurnal profiles of different processes (i.e., HADV, VDIF, CHEM and AERO) inside the planetary boundary layer indicated the transport of mercury from urban to non-urban areas. Moreover, it was found that gas-phase and aerosol chemistry (CHEM and AERO) have a large impact on GOM and PBM concentrations inside the free troposphere. The high concentration of GOM aloft in non-urban areas could be diffused downwards by VDIF. Most anthropogenic sources caused mercury to be transported and diffused away from urban areas by HADV and VDIF and increased the concentration in non-urban areas by HADV. In contrast, emissions from PP increased surface GOM concentration by VDIF because emission from PP led to a large concentration center at higher elevation. Natural sources only influenced CHEM and AERO in both areas more significantly than anthropogenic sources. Local emission in the YRD contributed $8.5 \%$ more to GEM and $~ 30 \%$ more to GOM and PBM in urban than in non-urban areas

Acknowledgements. This work was supported by the National Key Basic Research Development Program of China (2014CB441203, 2011CB403406), the Specialized Research Fund for the Doctoral Program of Higher Education of China (20110091110010) and a project funded by the Priority Academic Program Development of Jiangsu Higher Education Institutions (PAPD). Thanks to Shuxiao Wang and Long Wang from Tsinghua University for providing mercury emission data.

Edited by: L. Zhang

\section{References}

Bieser, J., De Simone, F., Gencarelli, C., Geyer, B., Hedgecock, I., Matthias, V., Travnikov, O., and Weigelt, A.: A diagnostic evaluation of modeled mercury wet depositions in Europe using atmospheric speciated high-resolution observations, Environ. Sci. Pollut. R., 21, 9995-10012, 2014.

Binkowski, F. S. and Roselle, S. J.: Models-3 Community Multiscale Air Quality (CMAQ) model aerosol component 1. Model description, J. Geophys. Res., 108, 4183-4201, doi:10.1029/2001JD001409, 2003.

Bullock, O. R. J. and Brehme, K. A.: Atmospheric mercury simulation using the CMAQ model: formulation description and analysis of wet deposition results, Atmos. Environ., 36, 2135-2146, doi:10.1016/S1352-2310(02)00220-0, 2002.

Bullock, O. R., Atkinson, D., Braverman, T., Civerolo, K., Dastoor, A., Davignon, D., Ku, J.-Y., Lohman, K., Myers, T. 
C., Park, R. J., Seigneur, C., Selin, N. E., Sistla, G., and Vijayaraghavan, K.: The North American Mercury Model Intercomparison Study (NAMMIS): Study description and model-to-model comparisons, J. Geophys. Res., 113, D17310, doi:10.1029/2008JD009803, 2008.

Bullock, O. R., Atkinson, D., Braverman, T., Civerolo, K., Dastoor, A., Davignon, D., Ku, J.-Y., Lohman, K., Myers, T. C., Park, R. J., Seigneur, C., Selin, N. E., Sistla, G., and Vijayaraghavan, K.: An analysis of simulated wet deposition of mercury from the North American Mercury Model Intercomparison Study, J. Geophys. Res., 114, D08301, doi:10.1029/2008JD011224, 2009.

Chen, L., Liu, M., Xu, Z., Fan, R., Tao, J., Chen, D., Zhang, D., Xie, D., and Sun, J: Variation Trends and Influencing Factors of Total Gaseous Mercury Inthe Pearl River Delta-A Highly Industrialised Region in South Chinainfluenced by Seasonal Monsoons, Atmos. Environ., 77, 757-766, 2013.

Ci, Z. J., Zhang, X. S., Wang, Z. W., and Niu, Z. C.: Atmospheric gaseous elemental mercury (GEM) over a coastal/rural site downwind of East China: temporal variation and long-range transport, Atmos. Environ., 45, 2480-2487, 2011 a.

Ci, Z. J., Zhang, X. S., Wang, Z. W., Niu, Z. C., Diao, X. Y., and Wang, S. W.: Distribution and air-sea exchange of mercury $(\mathrm{Hg})$ in the Yellow Sea, Atmos. Chem. Phys., 11, 2881-2892, doi:10.5194/acp-11-2881-2011, 2011 b.

Cohen, M., Artz, R., Draxler, R., Miller, P., Poissant, L., Niemi, D., Ratté, D., Deslauriers, M., Duval, R., Laurin, R., Slotnick. J., Nettesheim, T., and McDonald, J.: Modeling the atmospheric transport and deposition of mercury to the Great Lakes, Environ. Res., 95, 247-265, 2004.

Dou, H., Wang, S., Wang, L., Zhang, L., and Hao, J.: Characteristics of Total Gaseous Mercury Concentrations at a Rural Site of Yangtze Delta, China, Environ. Sci., 34, 1-7, 2013 (in Chinese).

Feng, X., Shang, L., Wang, S., Tang, S., and Zheng, W.: Temporal variation of total gaseous mercury in the air of Guiyang, China, J. Geophys. Res., 109, D03303, doi:10.1029/2003JD004159, 2004.

Friedli, H. R., Arellano Jr., A. F., Geng, F., Cai, C., and Pan, L.: Measurements of atmospheric mercury in Shanghai during September 2009, Atmos. Chem. Phys., 11, 3781-3788, doi:10.5194/acp-11-3781-2011, 2011.

Fu, X. W., Feng, X. B., Zhu, W. Z., Wang, S. F., and Lu, J.: Total gaseous mercury concentrations in ambient air in the eastern slope of Mt. Gongga, South-Eastern fringe of the Tibetan plateau. China, Atmos. Environ., 42, 970-979, 2008.

Gbor, P. K., Wen, D., Meng, F., Yang, F., Zhang, B., and Sloan, J. J.: Improved model for mercury emission, transport and deposition, Atmos. Environ., 40, 973-983, 2006.

Gbor, P., Wen, D., Meng, F., Yang, F., and Sloan, J.: Modeling of mercury emission, transport and deposition in North America, Atmos. Environ., 41, 1135-1149, doi:10.1016/j.atmosenv.2006.10.005, 2007.

Holloway, T., Voigt, C., Morton, J., Spak, S. N., Rutter, A. P., and Schauer, J. J.: An assessment of atmospheric mercury in the Community Multiscale Air Quality (CMAQ) model at an urban site and a rural site in the Great Lakes Region of North America, Atmos. Chem. Phys., 12, 7117-7133, doi:10.5194/acp-12-71172012, 2012.

Keeler, G. J., Gratz, L. E., and Al-Wali, K.: Long-term Atmospheric Mercury Wet Deposition at Underhill, Vermont, Ecotoxicology, 14, 71-83, 2005.
Lin, X. and Tao, Y.: A numerical modelling study on regional mercury budget for eastern North America, Atmos. Chem. Phys., 3, 535-548, doi:10.5194/acp-3-535-2003, 2003.

Lin, C. J. and Pehkonen, S. O.: The chemistry of atmospheric mercury: A review, Atmos. Environ., 33, 2067-2079, 1999.

Lin, C.-J., Pan, L., Streets, D. G., Shetty, S. K., Jang, C., Feng, X., Chu, H.-W., and Ho, T. C.: Estimating mercury emission outflow from East Asia using CMAQ-Hg, Atmos. Chem. Phys., 10, 1853-1864, doi:10.5194/acp-10-1853-2010, 2010.

Lin, C. J., Shetty, S. K., Pan, L., Pongprueksa, P., Jang, C., and Chu, H.: Source attribution for mercury deposition in the contiguous United States: Regional difference and seasonal variation, J. Air Waste Manage, 62, 52-63, 2012.

Lindberg, S. E., Brooks, S., Lin, C. J., Scott, K. J., Landis, M. S., Stevens, R. K., Goodsite, M., and Richter, A.: Dynamic oxidation of gaseous mercury in the arctic troposphere at polar sunrise, Environ. Sci. Technol., 36, 1245-1256, doi:10.1021/es0111941, 2002.

Liu, X. and Zhang, Y: Understanding of the formation mechanisms of ozone and particulate matter at a fine scale over the southeastern U.S.: Process analyses and responses to future-year emissions, Atmos. Environ., 74, 259-276, 2013.

Nguyen, D., Kim, J., Shim, S., and Zhang, X.: Ground and shipboard measurements of atmospheric gaseous elemental mercury over the Yellow Sea region during 2007-2008, Atmos. Environ., 41, 253-260, 2011.

Pacyna, E. G., Pacyna, J. M., Sundseth, K., Munthe, J., Kindbom, K., Wilson, S., Steenhuisen, F., and Maxson, P.: Global emission of mercury to the atmosphere from anthropogenic sources in 2005 and projections to 2020, Atmos. Environ., 44, 2487-2499, 2010.

Pai, P., Karamchandani, P., Seigneur, C., and Allan, M.: Sensitivity of simulated atmospheric mercury concentrations and deposition to model input parameters, J. Geophys. Res., 104, 13855-13868, 1999.

Pan, L., Lin, C. J., Carmichael, G. R., Streets, D. G., Tang, Y., Woo, J. H., Shetty, S. K., Chu, H. W., Ho, T. C., Friedli, H. R., and Feng, X.: Study of atmospheric mercury budget in East Asia using STEM-Hg modeling system, Sci. Total Environ., 408, 32773291, 2010.

Pongprueksa, P., Lin, C. J., Lindberg, S. E., Jang, C., Braverman, T., Russell Bullock Jr., O., Ho, T. C., and Chu, H. W.: Scientific uncertainties in atmospheric mercury models III: boundary and initial conditions, model grid resolution, and $\mathrm{Hg}(\mathrm{II})$ reduction mechanism, Atmos. Environ., 42, 1828-1845, 2008.

Quan, J., Zhang, Q., and Zhang, X.: Emission of Hg from coal consumption in China and its summertime deposition calculated by CMAQ-Hg, Terr. Atmos. Ocean. Sci., 20, 325-331, 2009.

Rolfhus, K. R., Sakamoto, H. E., Cleckner, L. B., Stoor, R. W., Babiarz, C. L., Back, R. C., Manolopoulos, H., and Hurley, J. P.: Distribution and fluxes of total and methyl mercury in Lake Superior, Environ. Sci. Technol., 37, 865-872, 2003.

Sarwar, G., Luecken, D., Yarwood, G., Whitten, G. Z., and Carter, W. P. L.: Impact of an Updated Carbon Bond Mechanism on Predictions from the CMAQ Modeling System: Preliminary Assessment, J. Appl. Meteorol. Clim., 47, 3-14, doi:10.1175/2007JAMC1393.1, 2008.

Schroeder, W. H. and Munthe, J.: Atmospheric mercury - an overview, Atmos. Environ., 32, 809-822, 1998. 
Seigneur, C., Vijayaraghavan, K., Lohman, K., Karamchandani, P., and Scott, C.: Global Source Attribution for Mercury Deposition in the United States, Environ. Sci. Technol., 38, 555-569, 2004.

Selin, N. E. and Jacob, D. J.: Seasonal and spatial patterns of mercury wet deposition in the United States: constraints on the contribution from North American anthropogenic sources, Atmos. Environ., 42, 5193-5204, 2008.

Selin, N. E., Jacob, D. J., Park, R. J., Yantosca, R. M., Strode, S., Jaegle, L., and Jaffe, D.: Chemical cycling and deposition of atmospheric mercury: Global constraints from observations, J. Geophys. Res.-Atmos., 112, D02308, doi:10.1029/2006jd007450, 2007.

Shetty, S., Lin, C., Streets, D., and Jang, C.: Model estimate of mercury emission from natural sources in East Asia, Atmos. Environ., 42, 8674-8685, 2008.

Streets, D. G., Zhang, Q., and Wu, Y.: Projections of global mercury emissions in 2050, Environ. Sci. Technol., 36, 2983-2988, 2009.

Wan, Q., Feng, X. B., Lu, J. L., Zheng, W., Song, X. J., Li, P., Han, $\mathrm{S}$. J., and $\mathrm{Xu}, \mathrm{H}$.: Atmospheric mercury in Changbai Mountain area, northeastern China I: the season distribution pattern of total gaseous mercury and its potential sources, Environ. Res., 109, 201-206, 2009

Wang, L., Wang, S., Zhang, L., Wang, Y., Zhang, Y., Nielsen, C., McElroy, M. B., and Hao, J.: Source apportionment of atmospheric mercury pollution in China using the GEOS-Chem model, Environ. Pollut., 190, 166-175, 2014.

Wang, Y.: The speciation, levels and potential impacted factors of atmospheric mercury in Hefei, Central China, University of Science and Technology of China, 2010 (in Chinese).

Wang, S. X., Zhang, L., Wang, L., Wu, Q. R., Wang, F. Y., and Hao, J. M.: A review of atmospheric mercury emissions, pollution and control in China, Front. Environ. Sci. Eng., 8, 631-649, doi:10.1007/s11783-014-0673-x, 2014.
Wang, Z. W., Chen, Z. S., Duan, N., and Zhang, X. S.: Gaseous elemental mercury concentration in atmosphere at urban and remote sites in China, J. Environ. Sci., 19, 176-180, 2007.

Wu, Y., Wang, S., Streets, D. G., Hao., J., Chan, M., and Jiang, J.: Trends in Anthropogenic Mercury Emissions in China from 1995 to 2003, Environ. Sci. Technol., 40, 5312-5318, 2006.

Wu, Q. R., Wang, S. X., Zhang, L., Song, J. X., Yang, H., and Meng, Y.: Update of mercury emissions from China's primary zinc, lead and copper smelters, 2000-2010, Atmos. Chem. Phys., 12, 11153-11163, doi:10.5194/acp-12-11153-2012, 2012.

Xiu, G., Cail, J., Zhang, W., Zhang, D., Bueler, A., Lee, S., Shen, Y., Xu, L., Hunag, X., and Zhang, P.: Speciated mercury in sizefractionated particles in Shanghai ambient air, Atmos. Environ., 43, 3145-3154, 2009.

Zhang, L., Wang, S. X., Wang, L., and Hao, J. M.: Atmospheric mercury concentration and chemical speciation at a rural site in Beijing, China: implications of mercury emission sources, Atmos. Chem. Phys., 13, 10505-10516, doi:10.5194/acp-1310505-2013, 2013.

Zhu, J., Wang, T., Talbot, R., Mao, H., Hall, C. B., Yang, X., Fu, C., Zhuang, B., Li, S., Han, Y., and Huang, X.: Characteristics of atmospheric Total Gaseous Mercury (TGM) observed in urban Nanjing, China, Atmos. Chem. Phys., 12, 12103-12118, doi:10.5194/acp-12-12103-2012, 2012.

Zhu, J., Wang, T., Talbot, R., Mao, H., Yang, X., Fu, C., Sun, J., Zhuang, B., Li, S., Han, Y., and Xie, M.: Characteristics of atmospheric mercury deposition and size-fractionated particulate mercury in urban Nanjing, China, Atmos. Chem. Phys., 14, 2233 2244, doi:10.5194/acp-14-2233-2014, 2014. 